\title{
URGENSI PARENTING EDUCATION BERBASIS E-LEARNING DI ERA DIGITAL
}

\author{
Siful Arifin \\ Institut Kariman Wirayudha (INKADHA) Sumenep \\ Ach. Syaiful \\ Institut Kariman Wirayudha (INKADHA) Sumenep
}

\begin{abstract}
Artikel ini membahas tentang pentingnya Parenting Education berbasis elearning bagi orang tua. Salah satu alasan yang melatarbelakangi penulisan artikel ini adalah masih banyaknya orang tua yang belum mengetahui, memahami dan belum bisa menggunakan media teknologi informasi sebagai salah satu sarana dan media di dalam melakukan pengasuhan dan pendidikan. Oleh karena itu, Dalam artikel ini diajukan beberapa argumen yang bisa dijadikan landasan untuk melaksanakan Parenting Education berbasis e-learning di era digital. Pertama, Sebagai upaya preventif agar tidak terjadi malapraktik pengasuhan/pendidikan di lingkungan keluarga. Kedua, Program tersebut mempunyai pengaruh signifikan terhadap keberhasilan pengasuhan dan pendidikan di era digital. Ketiga, program tersebut dapat membantu orang tua dan guru dalam melakukan pendampingan, pengasuhan dan pendidikan tanpa ada hambatan teknologis, serta dapat membantu orang tua mempunyai pengetahuan, pemahaman dan keterampilan dalam melakukan proses pengasuhan, pendidikan dan pembelajaran berbasis e- learning.
\end{abstract}

Keywords: Parenting Education, e-learning, Era Digital

\section{Pendahuluan}

Dalam beberapa dekade belakangan ini, seiring dengan perkembangan teknologi yang begitu cepat dunia pendidikan terutama proses pembelajaran mengalami perubahan yang sangat signifikan. Misalnya, ketika beberapa Negara termasuk Indonesia dilanda Pandemi Covid-19, secara tiba-tiba pemerintah 
Siful Arifin dan Ach. Syaiful

memberlakukan pembelajaran jarak jauh (distance learning), belajar dari rumah dalam bentuk pembelajaran dalam jaringan (Daring) atau pembelajaran online.

Banyak orang tua siswa yang tidak siap menghadapi aturan baru ini. Tidak sedikit orang tua siswa yang kebingungan dalam mendampingi anaknya belajar dengan model pembelajaran berbasis e-learning. Hal ini terjadi karena masih banyak orang tua yang belum mengerti tentang media teknologi dan media sosial yang digunakan dalam pembelajaran berbasis e-learning. Efeknya pembelajaran daring atau online berbasis e-learning tidak efektif. Kasus ini banyak terjadi di sekolah-sekolah tingkat pendidikan anak usia dini dan ditingkat pendidikan dasar dimana para siswa perlu didampingi oleh orang tuanya dalam melaksankan proses pembelajaran yang berbasis e-learning.

Padahal keikutsertaan orang tua dalam proses pendidikan seorang anak adalah sebuah keniscayaan. Pendidikan seorang anak tidak bisa begitu saja diserahkan kepada sekolah atau lembaga pendidikan lainnya, karena kehidupan seorang anak tidak hanya berlangsung di sekolah tapi juga di rumah. Oleh karena itu, memadukan pendidikan di sekolah dan di rumah merupakan suatu keharusan. Kemendikbud RI memaparkan hasil studi World Bank (2013), bahwa keluarga memiliki manfaat kunci karena intervensi yang dilakukan terhadap anggota keluarganya dalam masalah pendidikan telah berhasil meningkatkan pencapaian perkembangan peserta didik sesuai dengan yang diharapkan. ${ }^{1}$

Dengan demikian maka, tidak hanya seorang guru yang dituntut mempunyai ilmu mendidik tapi orang tua juga dituntut untuk memilikinya. Secara formal seorang guru sudah dianggap memiliki ilmu mendidik melalui pendidikan formal yang ditempuhnya, namun tidak demikian dengan orang tua. Banyak orang tua yang belum mengetahui ilmu tentang mendidik dan mengasuh. Dari sisi inilah maka, Parenting education (pendidikan bagi orang tua) bisa menjadi alternatif agar orang tua bisa melakukan pengasuhan dan pendidikan yang baik bagi anaknya.

Sebenarnya parenting education bukanlah gagasan baru, program ini sudah dilaksanakan oleh beberapa sekolah dan lembaga pendidikan lainnya, terutama lembaga pendidikan yang mengelola Pendidikan Anak Usia Dini. Selama ini, pelaksanaan program parenting education sangat variatif. Misalnya dalam bentuk parent gatering, seminar, field trip dan lain sebagainya. Namun seiring berjalannya waktu dan perkembangan teknologi maka pelaksanaan parenting education terus

\footnotetext{
1 Kemendikbud Direktorat Jenderal PAUD dan Dikmas, 2015, Roadmap Pendidikan Keluarga, (Jakarta : Kemendikbud RI), h.1
}

42 | Kariman, Volume 08, Nomor 01, Juni 2020 
Siful Arifin dan Ach. Syaiful

perlu disesuaikan dengan kebutuhan dan keadaan. Misalnya dengan melaksanakan parenting education berbasis e-learning.

Pelaksanaan kegiatan belajar jarak jauh berbasis e-learning bukan hanya karena ada kasus pandemi Covid-19 saja, tapi diprediksi akan terus dilaksanakan di masa-masa yang akan datang. Oleh karena itu, perlu dipersiapkan unit-unit keluarga yang paham terhadap seluk-beluk teknologi mulai dari jenisnya, penggunaanya, manfaatnya serta efek positif dan negatifnya.

Dari paparan di atas, maka diperlukan adanya Parenting education berbasis e- learning. Hal ini perlu dilakukan untuk mengantisipasi adanya keluarga yang buta terhadap dunia teknologi. Fenomena di lapangan menunjukkan bahwa kegiatan parenting education berbasis e-learning belum banyak dilakukan. Padahal kegiatan tersebut sangat perlu dilakukan untuk membantu para orang tua melakukan pendidikan dan pengasuhan yang baik terhadap keluarganya di era digital.

\section{Mengenal Parenting Education}

Parenting education merupakan istilah yang digunakan untuk suatu kegiatan pendidikan yang dikhususkan bagi para orang tua siswa. Dalam tinjauan bahasa, istilah ini berasal dari bahasa Inggris yang terdiri dari dua kata yakni parenting ${ }^{2}$ dan education. Dalam bahasa Indonesia parenting berarti pengasuhan. Arti ini merupakan arti kontekstual bukan arti tekstual. Sedangkan education berarti pendidikan. Kemudian dua kata ini digabung menjadi parenting education yang berarti pendidikan tentang pola pengasuhan. Istilah lain yang digunakan untuk menyebut parenting education adalah school parenting, parenting club dan parenting school. $^{3}$ Dalam penggunaannya, istilah-istilah tersebut kadang-kadang hanya disebut dengan istilah parenting, tanpa ada tambahan kata lainnya. Dalam bahasa Arab istilah parenting education dapat dipersamakan dengan istilah Tarbiyah al-Aulad, yang berarti mendidik anak.

Dari segi istilah, parenting mempunyai banyak definisi. Ada beberapa ahli yang sudah mendeskripsikannya. Salah satunya adalah Brook dan Morrison, Sebagaimana dikutip oleh Adiyati Fathu Roshonah. Menurut Adiyati, parenting dalam pandangan Brooks adalah the process or the state of being a parent, sementara definisi lain yang dikutip oleh Adiyati adalah parenting menurut Morrison.

\footnotetext{
${ }^{2}$ Parenting berasal dari kata parent (Bhs.Inggris) yang berarti orang tua. Lihat, John M. Echols dan Hassan Shadily, Kamus Inggris Indonesia, ( Jakarta: Gramedia Pustaka Utama, 2005), h. 418

${ }^{3}$ Siti Nur Mauanah, Suprijono Agus, Parenting Education sebagai Pendidikan Keluarga (Motiv Keterlibatan Orang Tua Dalam Parenting Education), Paradigma. Volume 04 Nomer 01 Tahun 2016.
} 
Siful Arifin dan Ach. Syaiful

Parenting dalam definisi yang diajukan Morissson adalah the process of developing and utilising the knowledge and skills appropriate to planning for, creating, giving birth to, rearing and/or providing care for offspring atau sebuah proses mengembangkan dan memanfaatkan pengetahuan dan keterampilan yang tepat untuk merencanakan, menciptakan, melahirkan, membesarkan dan atau menyediakan perawatan untuk anak. $^{4}$

Definisi tentang parenting di atas belum sepenuhnya menggambarkan tentang parenting education yang dimaksudkan dalam artikel ini. Oleh karena itu, perlu dipaparkan definisi lain yang mungkin lebih dekat pengertiannya. Definisi Scott dan Gardner tentang program parenting lebih sesuai dengan apa yang dimaksudkan parenting education dalam artikel ini. Menurut Scott dan Gardner ${ }^{5}$

"A parenting program is a specific intervention designed to improve the overall quality of parenting that a child receives. Parenting programs aim to help the way mothers and fathers relate to their child".

Definisi lain yang mempunyai maksud sama dengan parenting education adalah apa yang diuraikan dalam Child Welfare Information Gateway ${ }^{6}$ berikut ini:

"While parenting may come naturally to some, others may need additional support and guidance to understand child development, to respond appropriately to their child's needs, and to cope with the challenges of parenting. Parent education provides caregivers with knowledge, resources, and support to develop parenting skills to enhance child and family well-being. It can also help parents or caregivers learn the tools and strategies to provide a positive and nurturing home environment where their children will thrive physically, emotionally, and cognitively"

Definisi lain disebutkan dalam Juknis Orientasi Teknis Peningkatan Program Parenting Tahun 2011, Program parenting adalah program dukungan yang ditunjukkan kepada para orang tua atau anggota keluarga yang lain agar semakin memiliki kemampuan dalam melaksanakan fungsi sosial dan pendidikan dalam hal mengasuh, merawat, melindungi, dan mendidik anaknya di rumah sehingga

\footnotetext{
${ }^{4}$ Adiyati Fathu Roshonah, Urgensi Program Pelatihan Parenting dalam Meningkatkan Kemampuan Komunikasi Orangtua dengan Anak, AL-MURABBI: Jurnal Studi Kependidikan dan Keislaman - Vol 5, No. 2, 2019.

${ }^{5}$ Stephen Scott and Frances Gardner, Parenting Program, on Rutter's Child and Adolescent Psychiatry, SixthEdition, Edited by AnitaThapar et al, (London : John Wiley \& Sons, Ltd., London, 2015), h. 483.

${ }^{6}$ Child Welfare Information Gateway, Parent Education to Strengthen Families and Reduce the Risk of Maltreatment, (Washington : Children's Bureau, Maryland Avenue, 2013), h. 2.
}

44 | Kariman, Volume 08, Nomor 01, Juni 2020 
anak dapat tumbuh dan berkembang secara optimal, sesuai dengan usia dan tahap perkembangannya. ${ }^{7}$

Dari beberapa pengertian di atas dapat dipahami bahwa parenting education adalah pendidikan bagi para orang tua yang mengkaji tentang pola dan cara pengasuhan anak. Dalam parenting education orang tua dibekali pengetahuan dan keterampilan agar mampu mengasuh anak dengan baik, benar dan tepat.

Dalam tinjauan ilmu pendidikan, parenting education merupakan salah satu bagian dari andragogi, yakni ilmu pendidikan yang membahas tentang pendidikan bagi orang dewasa. Namun pada umumnya, parenting education lebih dikhususkan bagi orang tua yang sudah mempunyai anak meskipun ada juga yang berpendapat bahwa parenting education tidak hanya dikhususkan kepada orang tua yang sudah mempunyai anak tapi juga kepada pengasuh anak dan lain sebagainya. ${ }^{8}$ Argumen bahwa parenting education tidak hanya diberikan kepada orang tua mempunyai landasan penguat jika parent diartikan sebagaimana diartikan oleh Brooks. Menurut Brooks sebagaimana dikutip oleh Resiana Nooraeni, parent dalam parenting memiliki beberapa definisi yakni ibu, ayah, seseorang yang akan membimbing dalam kehidupan baru, seorang penjaga, maupun seorang pelindung. Parent adalah seseorang yang mendampingi dan membimbing semua tahapan pertumbuhan anak, yang merawat, melindungi, mengarahkan kehidupan baru anak dalam setiap tahapan perkembangannya. ${ }^{9}$ Namun parenting education yang dimaksudkan dalam artikel ini adalah parenting education yang dikhususkan bagi para orang tua.

\section{Tipologi Parenting}

Dalam melakukan pengasuhan, setiap orang tua mempunyai tipe dan gaya yang berbeda-beda antara satu dengan yang lainnya. Diana Baumrind sebagaimana dijelaskan oleh Thomas G. Power, bahwa ada 3 gaya pengasuhan. Diantaranya adalah otoritatif, otoriter, permisif..$^{10}$ Berikut ini adalah penjelasan dari 3 gaya pengasuhan tersebut.

1. Authoritarian parenting atau pola asuh otoriter, dalam pengasuhan gaya otoritarian ini orang tua digambarkan sebagai seseorang yang otoriter. Dia hanya mengatur, mengontrol dan dan mengevaluasi setiap tindakan anaknya agar

\footnotetext{
7 Asep Saepudin dan Saly Ulfah: Penerapan Program Parenting Berbasis E-Learning dalam Mengembangkan Kemampuan Mendidik Anak, Jurnal Teknodik Vol. 18 - Nomor 3, Desember 2014, h. 244.

${ }^{8}$ Lihat Resiana Nooraeni, Implementasi Program Parenting Dalam Menumbuhkan Perilaku Pengasuhan Positif Orang Tua di PAUD Tulip Tarogong Kaler Garut. Jurnal Pendidikan Luar Sekolah Volume 13, Nomor 2, Oktober 2017. h. 32 .

${ }^{9}$ Resiana Nooraeni, Implementasi Program......h.32

${ }^{10}$ Thomas G. Power, Parenting Dimensions and Styles: A Brief History and Recommendations for Future Research, CHILDHOOD OBESITY, August 2013 j Volume 9, Supplement 1. h.17.
}

Kariman, Volume 08, Nomor 01, Juni $2020 \mid 45$ 
Siful Arifin dan Ach. Syaiful

sesuai dengan aturan yang dikehendaki oleh orang tua. Dalam gaya pengasuhan ini seorang anak dipaksa untuk selalu tunduk kepada orang tuanya. Pola pengasuhan seperti ini mempunyai pengaruh negative terhadap perkembangan mental anak.

2. Authoritative parenting atau pola asuh demokratis; gaya pengasuhan otoritatif merupakan gaya pengasuhan dimana orang tua cenderung memperoritaskan kepentingan anak dan bertindak secara rasional. Orang tua tidak mengekang dengan aturan-aturan tertentu tapi selalu mengarahkan dan memberi penjelasan tentang tindakan dan konsekuensi dari tindakan yang akan dan telah dilakukan oleh anaknya. Pola pengasuhan ini selalu berusaha agar anak bertindak dengan penuh kesadaran dan bertanggung jawab atas semua yang telah dilakukannya.

3. Indulgent atau Permissive parenting; gaya asuh yang ketiga ini disebut pola asuh pemanja. Dalam pola pengasuhan ini orang tua cenderung memberi kebebasan kepada anak-anaknya dalam melakukan tindakan. Anak diberi kebebasan untuk mengatur dirinya. Dalam gaya pengasuhan permisif ini orang tua tidak menuntut tanggung jawab terhadap tindakan anaknya meskipun tindakan itu salah dan orang tua cenderung tidak bisa mengontrol dan mengarahkan anaknya.

Selain 3 pola asuh di atas, ada juga pola asuh Indifferent atau Pola Asuh Penelantar. Ciri utama dari pola asuh ini adalah orang tua hanya mempunyai waktu berinterkasi yang sedikit dengan anak-anaknya. Orang tua lebih mementingkan kepentingannya sendiri dan membiarkan anaknya berkembang dengan sendirinya.

Dari beberapa gaya tipologi di atas, pola asuh Indulgent atau Permissive parenting dan pola asuh Indifferent Pola Asuh Penelantar adalah pola asuh yang sebaiknya dihindari oleh para orang tua. 2 pola asuh ini sangat tidak baik untuk diterapkan pada era digital seperti sekarang ini. Dalam konteks pembelajaran berbasis e-larning, seorang anak bisa menyalahkan gunakan media teknologi yang dioperasikannya. Sedangkan 2 pola asuh lainnya yakni Authoritarian parenting dan Authoritative parenting bisa diterapkan sesuai situasi dan kondisi perkembangan seorang anak. 


\section{Bentuk Kegiatan Parenting Education}

Parenting education dapat dilakukan dalam berbagai bentuk kegiatan. Pelaksanaan kegiatannya bersifat dinamis, bisa disesuaikan dengan kebutuhan, situasi dan kondisi. Menurut California Evidence-Based Clearinghouse (CEBC) \& Centers for Disease Control and Prevention (2009) sebagaimana dikutip oleh Adiyati ${ }^{11}$ bahwa kegiatan parenting dapat disampaikan secara individu atau dalam kelompok di rumah, ruang kelas, atau pengaturan lainnya. Pengaturan pelaksanaan dapat dilakukan secara fleksibel. Media yang dipergunakan bisa dalam bentuk tatap muka atau online, termasuk metode ceramah, instruksi langsung, diskusi, pemutaran video, perstrategian, atau format lain.

Kegiatan parenting education dapat dilaksanakan dalam berbagai bentuk kegiatan diantaranya adalah: ${ }^{12}$

1. think-thank dengan sumbang saran melalui berpendapat dan diskusi.

2. Arisan bicara

3. Seminar

4. Praktik keterampilan.

5. Outbond

6. Kunjungan lapangan.

Sementara Helmawati dalam bukunya yang berjudul "Mengenal dan memahami PAUD" menjelaskan bahwa program parenting education di lembaga PAUD dapat dilakukan dalam kegiatan-kegiatan berikut ini: ${ }^{13}$

1. Parents gathering; yaitu pertemuan orang tua dengan pihak lembaga PAUD untuk membicarakan program-program lembaga PAUD dalam kaitannya dengan bimbingan dan pengasuhan anak di keluarga. Materi yang dibahas dapat berupa hal yang berkaitan dengan kebutuhan tumbuh kembang anak yang terdiri dari kesehatan dan penyakit pada anak, gizi dan makanan maupun pendidikan karakter.

2. Field trip; yaitu darmawisata, kunjungan wisata, atau kunjungan ke tempattempat yang menunjang kegiatan pembelajaran PAUD yang dilakukan bersama orang tua.

\footnotetext{
${ }^{11}$ Adiyati Fathu Roshonah, Urgensi Program Pelatihan Parenting...127.

${ }^{12}$ Mefrida Harahap, "Program Parenting pada Kelompok Bermain", ipisumedang.blogspot.com/2012/04/programparenting-pada-kelompok-bermain.html (Rabu,05 juni 2020, $09.30 \mathrm{WIB}$ ).

${ }^{13}$ Helmawati. Mengenal dan Memahami PAUD. (Bandung: PT Remaja Rosdakarya. 2015), h. 63-64.
}

Kariman, Volume 08, Nomor 01, Juni 2020| 47 
Siful Arifin dan Ach. Syaiful

3. Seminar; yaitu kegiatan yang dilaksankan dalam rangka program parenting dengan mengundang tokoh atau praktisi PAUD yang berkompeten.

4. Foundation class; yaitu pembelajaran bersama anak dan orang tua di awal masuk sekolah dalam rangka orientasi dan pengenalan kegiatan di sekolah. Kegiatan ini dapat dilaksanakan pada minggu pertama tahun ajaran baru.

5. Hari konsultasi; yaitu hari yang disediakan oleh lembaga PAUD untuk orang tua untuk berkonsultasi tentang anaknya

6. Home activities; yaitu aktivitas rumah yang dilakukan di sekolah. Bentuk kegiatan ini dengan mengajak orang tua dan anak untuk menginap di sekolah yaitu dapat berupa kegiatan perkemahan.

7. Bazar day; yaitu penyelenggaraan kegiatan bazar di lembaga PAUD. Anakanak akan menampilkan hasil karyanya yang dapat dijual kepada orang tua dan umum.

8. Coocking on the spot; yaitu suatu kegiatan memasak dan mneyajikan makanan yang dilakukan anak bersama orang tua dengan bimbingan guru.

9. Mini zoo; yaitu menyelenggarakan kebun binatang mini di sekolah. Anak-anak dapat membawa binatang peliharaan dari rumah ke lembaga PAUD.

10. Home education video; yaitu mengirimkan kegiatan pembelajaran anakanak di lembaga PAUD kepada orang tua dalam bentuk keping CD/DVD, agar orang tua dapat menyaksikannya di rumah.

Selain kegiatan-kegitan di atas, program kegiatan parenting juga dapat berbentuk kegiatan-kegiatan alternatif lainnya sesuai dengan karakteristik dan keadaan lingkungan peserta didik dan orang tua. Misalnya di era teknologi seperti sekarang ini, dimana pembelajaran bisa dilaksanakan secara online maka sangat perlu untuk dilakukan kegiatan parenting yang berbasis e-learning. Misalnya dalam bentuk kegiatan teknologi day; yaitu suatu kegiatan yang mengajak peserta didik dan orang tua mengenal jenis teknologi dan fungsinya, khususnya media tekhnologi yang berkaitan dengan proses pembelajaran dan pengembangan diri. Selain itu, parenting education berbasis e-learning bisa dilakukan dalam bentuk Groupbased e-learning synchronously e-learning berbasis kelompok secara serentak. Tipe aktivitas belajar dalam pembelajaran e-learning ini bisa dalam bentuk diskusi online melalui media sosial seperti $W A$, messenger dll bisa juga dalam bentuk belajar mandiri. 


\section{Parenting Education Berbasis E-Learning}

Indonesia merupakan salah satu Negara dengan pengguna internet terbanyak di dunia. Kementerian Komunikasi dan Informatika (Kominfo) menyebut hingga Juni 2019 tercatat sebanyak 171 juta pengguna internet di Indonesia. Setiap tahun pengguna internet tumbuh 10,2 persen atau 27 juta jiwa. ${ }^{14}$

Gambaran tersebut merupakan fenomena yang bersifat dinamis. Ini merupakan fase dari setiap proses perkembangan era digital yang berkembang dari generasi ke generasi. Para orang tua yang lahir antara tahun 1960 sampai 1980 kita kenal dengan generasi $\mathrm{X}$. Generasi ini adalah generasi yang belum mengenal internet sehingga aktivitas mereka dilakukan secara mandiri tanpa ada bantuan internet, meski setelahnya teknologi muncul di akhir tahun 80-an. Sedangkan, generasi yang lahir di atas tahun 1980 hingga 1990 dikenal dengan generasi Y. Pada generasi inilah hiruk pikuk perkembangan teknologi seperti internet dan gadget muncul sehingga generasi ini lebih inovatif dan berpikiran terbuka dibandingkan dengan generasi X. Setelah generasi Y, kita kenal lagi generasi Z. Generasi ini lahir di akhir tahun 90-an, dimana terjadi ledakan inovasi teknologi di berbagai bidang dengan akses yang semakin mudah dan murah. ${ }^{15}$

Dari 3 jenis model generasi di atas, generasi $\mathrm{Z}$ merupakan generasi yang hampir pasti menghabiskan sebagian besar aktivitasnya melalui media teknologi dan jaringan internet. Dalam dunia pendidikan, aktivitas pembelajaran yang dilakukan dengan mengandalkan jaringan teknologi dan internet disebut dengan istilah e-learning (electronic learning). Para ahli mempunyai definisi yang variatif tentang konsep e-learning ini. Salah satunya Allan J. Henderson (2003) sebagaiman dikutip oleh Ratna eLearning diartikan sebagai pembelajaran jarak jauh yang menggunakan teknologi komputer atau biasanya disebut internet. ${ }^{16}$ Sementara Dong sebagaimana dikutip Kamarga mendefinisikan "Electronic Learning sebagai kegiatan belajar asynchronous melalui perangkat elektronik komputer yang tersambungkan ke internet dimana peserta belajar berupaya memperoleh bahan belajar yang sesuai dengan kebutuhannya. ${ }^{17}$

\footnotetext{
${ }^{14}$ https://www.gatra.com/detail/news/426059/teknologi/hingga-juni-2019-pengguna-internet-indonesia-171juta, diakses 23 april 2020.

${ }^{15}$ Nurul Azizah dkkk, Modul pelatihan di era digital, (Jakarta,Kementerian Pemberdayaan Perempuan Dan Perlindungan Anak Republik Indonesia, 2017), 17.

${ }^{16}$ Ratna Tiharita Setiawardhani, Pembelajaran Elektronik (E-Learning) Dan Internet Dalam Rangka Mengoptimalkan Kreativitas Belajar Siswa, Edunomic, Jurnal Ilmiah Pend. Ekonomi, Volume 1 Nomor 2, September 2013), h. 84 .

${ }^{17}$ Asep Saepudin dan Saly Ulfah: Penerapan Program Parenting.....h.245.
}

Kariman, Volume 08, Nomor 01, Juni $2020 \mid 49$ 
Siful Arifin dan Ach. Syaiful

Dari definisi di atas dipahami bahwa E-learning merupakan pembelajaran online yang didukung oleh jasa teknologi, audio, video tape, transmisi satelit atau komputer. Dalam perkembangannya, computer dipakai sebagai alat bantu pembelajaran, karena itu dikenal dengan istilah computer based learning (CBL) atau computer assisted learning (CAL). Teknologi pembelajaran terus berkembang dan dikelompokkan menjadi dua, yaitu; (1) Technology based learning yang terdiri dari Audio Information Technologies (radio, audio tape, voice mail, telephone) dan video information Technologies (misalnya; video tape, video text, video messaging), dan (2) Technology based Web learning pada dasarnya merupakan data information technologies (misalnya: bulletin board, internet, e-mail, telecollaboration). ${ }^{18}$

Sarana dan media teknologi di atas merupakan suatu perangkat yang tidak asing lagi bagi generasi $\mathrm{Z}$, yakni generasi yang dikenal dengan sebutan digital native. Digital native adalah gambaran bagi seseorang (terutama anak hingga remaja) yang sejak kelahirannya telah terpapar gencarnya perkembangan teknologi, seperti perkembangan komputer, internet, animasi, dan sebagainya yang terkait dengan teknologi. ${ }^{19}$ Kondisi ini tidak dialami oleh generasi-genarasi sebelumnya, sehingga wawasan pemikirannya berbeda dengan generasi $\mathrm{Z}$.

Dalam konteks pendidikan, hampir semua generasi $\mathrm{Z}$ mempunyai pandangan bahwa proses pendidikan dan pembelajaran bisa dilakukan melalui sarana teknologi dan jaringan internet. Misalnya melalui video youtube, media sosial dan media komunikasi lainnya. Pandangan ini tentu berbeda dengan pandangan generasi sebelumnya yang masih belum mengalami proses pembelajaran sebagaimana dialami oleh generasi $\mathrm{Z}$ atau yang dikenal dengan generasi digital native tersebut. Kondisi ini yang menyebabkan para orang tua yang kebanyakan adalah generasi sebelum generasi digital native mengalami kesulitan ketika harus mendampingi anaknya dalam pembelajaran daring. Tentu, kondisi ini tidak boleh dibiarkan begitu saja agar tidak terjadi turbulensi dalam proses pendidikan dan pengasuhan seorang anak. Disinilah letak penting dari adanya parenting education berbasis e-learning di era digital bagi orang tua.

Parenting education berbasis e-learning merupakan suatu program yang perlu segera dilaksanakan untuk membantu para orang tua yang mengalami kesulitan mendampingi anaknya dalam pembelajaran daring. Hal ini berkaca pada proses pembelajaran online selama masa libur covid-19 yang tidak berjalan secara

\footnotetext{
${ }^{18}$ Ibid.,

${ }^{19} \mathrm{Ibid}$,
}

50 | Kariman, Volume 08, Nomor 01, Juni 2020 
maksimal. Selain itu, Parenting education berbasis e-learning juga penting untuk dilaksanakan dalam rangka menimalisir adanya kesenjangan pemahaman teknologi antara orang tua dan anak. Melalui parenting education berbasis e learning, orang tua bisa mendapatkan pengetahuan dan pemahaman terkait dengan jenis dan penggunan media teknologi yang cocok untuk dijadikan media pembelajaran dan pengasuhan di rumah, baik di masa covid-19 maupun di masa pasca covid-19.

Lebih spesifik, manfaat dan tujuan dari Parenting education berbasis elearning adalah untuk meningkatkan kesadaran orang tua dalam melakukan pengasuhan anak di era digital. Pengasuhan anak di era digital berbeda dengan pola pengasuhan anak di era non-digital. Di era digital, anak tidak bisa dilarang untuk berinteraksi dengan produk-produk digital. Penggunaan produk digital merupakan sebuah keniscayaan. Oleh karena itu, orang tua bisa berperan sebagai fasilitator, tutor, evaluator dll.

Dalam Parenting education berbasis e-learning, orang tua bisa mempelajari metode, cara dan pendekatan yang bisa digunakan untuk melakukan pengasuhan anak sesuai dengan kebutuhan dan tingkat perkembangan seorang anak. Dengan adanya parenting education berbasis e-learning ini secara tidak langsung orang tua dapat membantu guru dan sekolah mencapai visi misi pendidikan yang ditetapkannya. Oleh karena itu, orang tua dan guru harus saling melakukan kerjasama dalam mewujudkan anak yang berkualitas melalui program parenting education berbasis e-learning.

\section{Kesimpulan}

Program parenting education berbasis e-learning merupakan cabang dari pendidikan orang dewasa. Program ini sangat cocok diberikan kepada para orang tua, terutama bagi yang belum mempunyai pengetahuan dan keterampilan tentang fungsi dan manfaat sarana teknologi informasi, agar mereka mempunyai wawasan, pengetahuan dan keterampilan dalam melakukan proses pengasuhan dan pendidikan. Melakukan pengasuhah dan pendidikan dengan memakai media atau sarana teknologi informasi adalah sebuah keniscayaan yang tidak bisa dihindari di era digital seperti sekarang ini.

Oleh karena itu, Program parenting education berbasis e-learning ini sangat penting dilaksanakan karena beberapa alasan salah satunya adalah agar orang tua mampu melakukan proses pengasuhan dan pendidikan tanpa ada hambatan teknologis dan tidak terjadi malapraktik pendidikan berbasis teknologi. Selain itu, program ini juga dapat mempermudah orang tua dan guru untuk saling 
Siful Arifin dan Ach. Syaiful

bekerjasama dalam melakukan proses pendampingan, pengasuhan dan pendidikan.

\section{DAFTAR PUSTAKA}

Child Welfare Information Gateway, Parent Education to Strengthen Families and Reduce the Risk of Maltreatment, Washington : Children's Bureau, Maryland Avenue, 2013.

Edwards, C. Drew. 2006. Ketika Anak Sulit Diatur: Panduan Bagi Para Orang Tua Untuk Mengubah Masalah Perilaku Anak. Bandung: PT. Mizan Utama.

Helmawati. Mengenal dan Memahami PAUD. Bandung: PT Remaja Rosdakarya. 2015.

Kemendikbud Direktorat Jenderal PAUD dan Dikmas, 2015, Roadmap Pendidikan Keluarga, (Jakarta : Kemendikbud RI.

Lestari, Ni Gusti Ayu Made Yeni, Program Parenting Untuk Menumbuhkan Kesadaran Pentingnya Keterlibatan Orang Tua Di Paud, Pratama Widya : Jurnal Pendidikan Anak Usia Dini Volume 4, No. 1, April 2019.

Mauanah Siti Nur, Suprijono Agus, Parenting Education sebagai Pendidikan Keluarga (Motiv Keterlibatan Orang Tua Dalam Parenting Education), Paradigma. Volume 04 Nomer 01 Tahun 2016.

Harahap, Mefrida, "Program Parenting pada Kelompok Bermain", ipisumedang.blogspot.com/2012/04/program-parenting-pada-kelompokbermain.html (Rabu,05 juni 2020, 09.30 WIB).

Martuti, Mengelola Pendidikan Anak Usia Dini. Yogyakarta: Kreasi Wacana, 2008.

Nurul Azizah dkkk, Modul pelatihan di era digital, (Jakarta: Kementerian Pemberdayaan Perempuan Dan Perlindungan Anak Republik Indonesia, 2017.

Roshonah, Adiyati Fathu, Urgensi Program Pelatihan Parenting dalam Meningkatkan Kemampuan Komunikasi Orangtua dengan Anak, ALMURABBI: Jurnal Studi Kependidikan dan Keislaman - Vol 5, No. 2, 2019. 
Siful Arifin dan Ach. Syaiful

Setiawardhani, Ratna Tiharita, Pembelajaran Elektronik (E-Learning) Dan Internet Dalam Rangka Mengoptimalkan Kreativitas Belajar Siswa, Edunomic, Jurnal Ilmiah Pend. Ekonomi, Volume 1 Nomor 2, September 2013.

Saepudin, Asep dan Saly Ulfah: Penerapan Program Parenting Berbasis E-Learning dalam Mengembangkan Kemampuan Mendidik Anak, Jurnal Teknodik Vol. 18 - Nomor 3, Desember 2014.

Sri Lestari, Psikologi Keluarga (Jakarta: Prenada Media Group, 2012.

Scott, Stephen and Frances Gardner, Parenting Program, on Rutter's Child and Adolescent Psychiatry, SixthEdition, Edited by AnitaThapar et al, (London : John Wiley \& Sons, Ltd., London, 2015.

https://www.childwelfare.gov/pubPDFs/parented.pdf\#page=1\&view=Int roduction

https://www.gatra.com/detail/news/426059/teknologi/hingga-juni-2019pengguna-internet-indonesia-171-juta, diakses 23 april 2020 
Siful Arifin dan Ach. Syaiful

54 | Kariman, Volume 08, Nomor 01, Juni 2020 